\title{
The Effect of Three Different Ages of Patients with Hip Fracture on their Quality of Life Comparative Study
}

\author{
Wesam Mohammed Mahmoud', Mimi Mohamed Mekkawy², Osama Ahmed Farouk ${ }^{3}$ \& Amna Abdallah \\ Desouky ${ }^{4}$. \\ 1. Clinical Demonstrator of Medical-Surgical Nursing, Faculty of Nursing, Assiut University, Egypt. \\ 2. Professor of Medical, Surgical Nursing, Faculty of Nursing, Assiut University, Egypt. \\ 3. Professor of Orthopedic Surgery, Faculty of Medicine, Assiut University, Egypt. \\ 4. lecturer of Medical, Surgical Nursing, Faculty of Nursing, Assiut University Egypt, Egypt.
}

\begin{abstract}
Background: Hip fractures are serious injuries that can lead to immobility and dependency, disability, mortality and negatively impact on patients' quality of life. Aim: To compare the effect of three different ages of patients with hip fracture on their quality life. Research design: Descriptive (comparative research) design was utilized to conduct this study. Subjects: The sample compromised from three different adult ages from patients with hip fracture. Thirty patients for each group. The first age group represents young adult $(18<40)$, the second middle age adult $(40<60)$, and the third older age adult $(\geq 60)$. Setting: Trauma department at Assiut University Hospital. Tools: (I) Patient assessment sheet, (II) Rand Short Form 36-Items questionnaire. Result: The mean score of quality of life of the first age group (95.63 \pm 1.299$)$ was more than the second and third age group $(93.36 \pm 2.370,83.46 \pm 18.024$ respectively) Conclusion: quality of life of the first age group was better than the second and third age groups. Recommendation: rehabilitation program should be developed and applied for older adult patients with hip fracture to improve their quality of life.
\end{abstract}

\section{Keywords: Comparative Study, Three Different Ages, Quality Of Life \& Hip Fracture.}

\section{Introduction}

A hip fracture is a break that occurs in the proximal end of the femur (thigh bone), near the hip joint (Lewiecki et al., 2018) It is the most common broken bone that requires hospitalization. Hip fractures are generally classified into three major types depending on the specific location of the fracture (femoral neck, intertrochanteric or sub trochanteric fractures) (Wiklund et al., 2016).

Moreover, the incidence of hip fractures increases with age. Below the age of 40 year they occur more frequently in men, generally from industrial trauma. In later life they occur more in women due to hormonal disturbance. In older adults; previous falls, living alone, smoking, low weight bearing activity levels, low bone density and deficiency of vitamin $\mathrm{D}$. All of these factors can cause loss of bone mass and occurrence of fracture (Sozen et al., 2017).

The vast majority of hip fractures are treated with surgical repair. The type of surgery depends on the location and severity of the fracture and the person's age. Extra capsular hip fractures are generally managed with internal fixation (dynamic hip screw or intramedullary nails). Intracapsular hip fractures are treated with either internal fixation or arthroplasty (Prieto et al., 2017). The purpose of surgical treatment is to enable patients to performe early activities, reduce complications, improve postoperative quality of life, prolong survival, and reduce postoperative mortality (Gjertsen et al., 2016).

Quality of life (QOL) has been defined as the perceived difference between what the conditions of life are and what they should be. It is a patientreported outcome usually measured with carefully designed and validated instruments such as short form 36 questionnaires. However, Hip fracture is one of the most important problems that can considerably affect the patient's quality of life. In the majority of elderly patients, the hip fracture seriously affects physical and mental functioning and exerts a severe impact on their health status (HS) and health-related quality of life (HRQoL) .In addition, the most older adult patients with an already-distressing health status (HS) become further debilitated by pain, loss of mobility, and inability to care for themselves (Prieto et al., 2017).

\section{Significance of the study}

In Assiut University Hospitals through year 2017, it was found that there were (357) patients with hip fracture admitted to trauma department. (Assiut Univrsity Hospital records, 2017) From the 
researcher's clinical training in this department; the researcher observed that many hip fracture patients with different age groups admitted to trauma department and most of them cannot regain their ambulatory status after hip fracture and usual activities which can affect on their quality of life.

\section{Aim of the Study}

To compare the effect of three different ages of patients with hip fracture on their quality life.

\section{Research question}

Is the age group of Patients with hip fracture affecting their Quality of life?

\section{Patients \& Methods \\ Research design}

Descriptive (comparative research) design was utilized to conduct this study.

\section{Setting}

The study was conducted in the trauma department at Assiut University Hospital.

\section{Sample}

The sample included three different ages from patients with hip fracture admitted to trauma department at Assuit University Hospital, thirty patients for each group. The first age group represents young adult that their age range from eighteen to less than forty years old, the second age group represents middle adult that their age range from forty to less than sixty years old, and the third age group represents older adult that their age more than or equal to sixty years old. The mortality rate after the hip fracture represents $5.5 \%$. Two patients died during the period of hospitalization due to deep venous thrombosis. Three patients died after 6 months due to bed sores, tumor and liver disease. These patients not expressed in the results as the researcher taked others instead of them.

Tools

Two tools utilized for data collection.

\section{I- Patient assessment sheet}

It was developed by the researcher based on the national and international literatures review to assess the demographic data of studied patients, past and current health history. It consisted of two parts:-

\section{Part 1: Demographic data}

This part included socio-demographic data of studied patients such as name, age, gender, level of education, occupation, and marital status.

\section{Part 2: Past \& current health history}

This part included past and current health history of studied patients such as comorbid disease, site of fracture, mechanism of injury, date of injury, causes of hip fracture, medical management and complications of hip fracture.

II. Rand short form (SF) 36 items questionnaire (Ware \& Sherbourne, 1992).

It is the commonly used instrument for measuring health related quality of life. The Arabic version of this scale was adopted in this study to assess quality of life for three different age groups of patients with hip fracture after one year since the onset of trauma (Al Abdulmohsin, Coons et al., 1997). It contains of 36 items grouped into eight domains: Physical functioning, role limitations due to physical problems, role limitations due to emotional problems, vitality, mental health, social functioning, pain and general health.

\section{Rand short form scoring}

Scoring the Rand 36-Item Health Survey is a twosteps process. First, preceded numeric values are recoded per the scoring key given in Table 1 . Note that all items are scored so that a high score defines a more favorable health state. In addition, each item is scored on a 0 to 100 range so that the lowest and highest possible scores are 0 and 100, respectively. Scores represent the percentage of total possible score achieved. In step 2, items in the same scale are averaged together to create the 8 scale scores. Table 2 lists the items averaged together to create each scale. Items that are left blank (missing data) are not taken into account when calculating the scale scores. Hence, scale scores represent the average for all items in the scale that the respondent answered.

For example, to measure the patient's pain level, add the scores from questions 21,22 . If a patient circled 4 on 21, 3 on 22 use (Step 1) to score them.

An answer of 4 to question 21 is scored as 40,3 to question 22 is scored as 50. The score for this block is $40+50=90$. Now we divide by the 2 answered questions to get a total of $45 \%$. Since a score of 100 represents no pain, the lower score of $45 \%$ suggests the patient is experiencing pain. All 8 scales are scored in the same way.

\section{Ethical approval}

Permission to carry out the study was obtained from the ethical committee of the Faculty of Nursing. An official letter was issued from the Dean of the Faculty of Nursing to the Head of the Orthopedic Department to collect the necessary data. Informed consent was obtained from patients or families that are willing to participate in the study after explanation of the nature and purposes of the study. Confidentiality and anonymity assured. Patients have the right to refuse to participate and/or withdraw from the study without any rational at any time.

\section{Content validity and reliability}

The content validity was done by 5 expertise opinions in medical surgical nursing and the orthopedic surgery fields, who reviewed the tools for clarity, relevancy, comprehensiveness, and understanding. Reliability of the rand short form was tested by using Cronbach's alpha test $>0.70$ (Zhang et al., 2012). 


\section{Pilot Study}

It was conducted on $10 \%$ of the study subjects in a selected setting for testing clarity, applicability and time needed to answer the data collection tools of the study. The data obtained from the pilot study were analyzed; no changes were done in the assessment sheet, so the $10 \%$ of subjects selected for the pilot study were included in the study.

\section{Procedure}

The study was carried out on 3 phases

I- The first phase (preparatory phase)

- An official permission to conduct this study was obtained from the head of trauma department at Assiut University Hospital.

- Preparation of the data collection tools was carried out by the researcher after extensive literature review (nursing and medical textbooks, journals, internet resources) at this phase.

- Patient agreement for voluntary participation was obtained orally. The purpose and the nature of the study were explained.

II- The second phase (Implementation phase) at initial interview the researcher introduced herself to the patients and/ or their families to initiate communication; explained the nature and purpose of the study. Patients have been visited daily by researcher during hospitalization to assess patients conditions from admission until discharge to fill out the patient assessment sheet (tool I).The researcher assessed the patients during the preoperative period for demographic data, comorbid diseases, mechanism of injury ,site of fracture, affected side ,causes of hip fracture, medical treatment and methods of immobilization such as traction then the researcher assessed all groups of patients' postoperatively for medical complications that may occur immediately after surgery such as wound infection, deep vein thrombosis, pneumonia and urinary tract infection which may later affect on their quality of life. The researcher was available in the morning shift at the clinical field for two days / week by rotation. Data collection was completed through 6 months that started in November, 2018 and ended in April, 2019 by details; data collection were completed during the following period: According to the first group $(18<40)$ and second group $(40<60)$; it taked four months that started in November, 2018 and ended in February, 2019. While the period needed for third group $(\geq 60)$ was six months that started in November, 2018 and ended in April, 2019.

\section{III- The third phase (Follow up phase)}

The researcher assessed all groups for surgical complications that may occur later after six months from surgery such as delayed union, mal union, non- union and/or a vascular necrosis. Also, the researcher assessed Quality of life for all patients' groups after one year since onset of the trauma by using (tool II).

\section{Statistical design}

Statistical analysis was done using IBM SPSS 19 ®. Data expressed as number, percentage, mean, standard deviation and one way a nova test. A probability level of 0.05 was adopted as a level of significance for testing the research question. 


\section{Results}

Table (1): Frequency distribution of demographic data of studied patients $(n=90)$

\begin{tabular}{|c|c|c|c|c|c|c|c|}
\hline Variables & \multicolumn{2}{|c|}{$\begin{array}{c}\text { First group } \\
(\mathrm{n}=30) \\
(18 \text { yrs }<40 \text { yrs })\end{array}$} & \multicolumn{2}{|c|}{$\begin{array}{c}\text { Second group } \\
(n=30) \\
(40<60 \text { yrs })\end{array}$} & \multicolumn{2}{|c|}{$\begin{array}{c}\text { Third group } \\
(n=30) \\
(\geq 60 y r s)\end{array}$} & P.V \\
\hline $\begin{array}{l}\text { Age } \\
\text { Mean } \pm \text { DS }\end{array}$ & \multicolumn{2}{|c|}{$28.06 \pm 8.166$} & \multicolumn{2}{|c|}{$53.13 \pm 3.785$} & \multicolumn{2}{|c|}{$64.46 \pm 1.136$} & $0.001 * *$ \\
\hline Gender & $\mathrm{N}$ & $\%$ & $\mathrm{~N}$ & $\%$ & $\mathrm{~N}$ & $\%$ & \\
\hline Male & 22 & 73.3 & 13 & 43.3 & 14 & 46.7 & \multirow{2}{*}{$0.049 *$} \\
\hline Female & 8 & 26.7 & 17 & 56.7 & 16 & $53.3 \%$ & \\
\hline \multicolumn{8}{|l|}{ Marital status } \\
\hline Single & 16 & 53.3 & 0 & 0 & 0 & 0 & \multirow{3}{*}{$0.001 * *$} \\
\hline Married & 14 & 46.7 & 30 & 100.0 & 26 & 86.7 & \\
\hline Widow & 0 & 0 & 0 & 0 & 4 & 13.3 & \\
\hline \multicolumn{8}{|l|}{ Education level } \\
\hline Illiterate & 1 & 3.3 & 16 & 53.3 & 20 & 66.7 & \multirow{4}{*}{$0.001 * *$} \\
\hline Read and write & 8 & 26.7 & 8 & 26.7 & 8 & 26.7 & \\
\hline Secondary education & 21 & 70.0 & 5 & 16.7 & 1 & 3.3 & \\
\hline University level & 0 & 0 & 1 & 3.3 & 1 & 3.3 & \\
\hline \multicolumn{8}{|l|}{ Occupation } \\
\hline Office work & 0 & 0 & 1 & 3.3 & 0 & 0 & \multirow{7}{*}{$0.001 * *$} \\
\hline Machine work & 1 & 3.3 & 0 & 0 & 0 & 0 & \\
\hline Farmer & 0 & 0 & 9 & 30.0 & 4 & 13.3 & \\
\hline Student & 7 & 23.3 & 0 & 0 & 0 & 0 & \\
\hline House wife & 8 & 26.7 & 17 & 56.7 & 16 & 53.3 & \\
\hline Not working & 2 & 6.7 & 2 & 6.7 & 8 & 26.7 & \\
\hline Other jobs & 12 & 40.0 & 1 & 3.3 & 2 & 6.7 & \\
\hline
\end{tabular}

(*) Statistically significant at $p<0.05$

(**) highly significant at 0.05

Table (2): Frequency distribution of studied patient in relation to their past health history $(\mathbf{n}=90)$

\begin{tabular}{|c|c|c|c|c|c|c|c|}
\hline \multirow{2}{*}{$\begin{array}{l}\text { Variables } \\
\text { Diabetes }\end{array}$} & \multicolumn{2}{|c|}{$\begin{array}{c}\text { First group } \\
(n=30) \\
(18 \text { yrs }<40 y r s)\end{array}$} & \multicolumn{2}{|c|}{$\begin{array}{c}\text { Second group } \\
(n=30) \\
(40<60 \text { yrs })\end{array}$} & \multicolumn{2}{|c|}{$\begin{array}{c}\text { Third group } \\
(n=30) \\
(\geq 60 y r s)\end{array}$} & \multirow[t]{2}{*}{ P.V } \\
\hline & $\mathrm{N}$ & $\%$ & $\mathrm{~N}$ & $\%$ & $\mathrm{~N}$ & $\%$ & \\
\hline Yes & 2 & 6.7 & 7 & 23.3 & 12 & 40.0 & \multirow{2}{*}{$.009 * *$} \\
\hline No & 28 & 93.3 & 23 & 76.7 & 18 & 60.0 & \\
\hline \multicolumn{8}{|l|}{ Hypertension } \\
\hline Yes & 1 & 3.3 & 4 & 13.3 & 15 & 50.0 & \multirow{2}{*}{$.001 * *$} \\
\hline No & 29 & 96.7 & 26 & 86.7 & 15 & 50.0 & \\
\hline \multicolumn{8}{|l|}{ Pulmonary disease } \\
\hline Yes & 0 & 0 & 2 & 6.7 & 1 & 3.3 & \multirow{2}{*}{$.355^{\mathrm{ns}}$} \\
\hline No & 30 & 100.0 & 28 & 93.3 & 29 & 96.7 & \\
\hline \multicolumn{8}{|l|}{ Tumor disease } \\
\hline Yes & 0 & 0 & 2 & 6.7 & 0 & 0 & \multirow{2}{*}{$.129^{\mathrm{ns}}$} \\
\hline No & 30 & 100.0 & 28 & 32.2 & 30 & 100.0 & \\
\hline \multicolumn{8}{|c|}{ Corticosteroid therapy } \\
\hline Yes & 0 & 0 & 4 & 13.3 & 0 & 0 & \multirow{2}{*}{$.364^{\mathrm{ns}}$} \\
\hline No & 30 & 100.0 & 26 & 86.6 & 30 & 100.0 & \\
\hline \multicolumn{8}{|l|}{ Smoking } \\
\hline Yes & 0 & 0 & 2 & 6.7 & 5 & 16.7 & \multirow{2}{*}{$.053 *$} \\
\hline No & 30 & 100.0 & 28 & 93.3 & 25 & 83.3 & \\
\hline
\end{tabular}

(*) Statistically significant at $p<0.05$ 
Table (3): Frequency distribution of studied patients in relation to their present health history $(\mathbf{n})=90)$.

\begin{tabular}{|c|c|c|c|c|c|c|c|}
\hline \multirow{2}{*}{$\begin{array}{c}\text { Variables } \\
\text { Mechanism of injury }\end{array}$} & \multicolumn{2}{|c|}{$\begin{array}{c}\text { First group } \\
(\mathrm{n}=30)(18 \text { yrs }<40 \mathrm{yrs})\end{array}$} & \multicolumn{2}{|c|}{$\begin{array}{c}\text { Second group } \\
(n=30)(40<60 \text { yrs })\end{array}$} & \multicolumn{2}{|c|}{$\begin{array}{c}\text { Third group } \\
(\mathrm{n}=30)(\geq 60 \mathrm{yrs})\end{array}$} & \multirow[t]{2}{*}{ P.V } \\
\hline & $\mathrm{N}$ & $\%$ & $\mathrm{~N}$ & $\%$ & $\mathrm{~N}$ & $\%$ & \\
\hline Fall on ground (FOG) & 6 & 20.0 & 26 & 86.7 & 29 & 96.7 & \multirow{3}{*}{$0.001 * *$} \\
\hline Fall from high $(\mathrm{FFH})$ & 7 & 23.3 & 3 & 10.0 & 1 & 3.3 & \\
\hline Motor car accident (MCA) & 17 & 56.7 & 1 & 3.3 & 0 & 0 & \\
\hline \multicolumn{8}{|l|}{ Affected side } \\
\hline Right & 12 & 40.0 & 16 & 53.3 & 17 & 56.7 & \multirow{2}{*}{$.393^{\mathrm{ns}}$} \\
\hline Lift & 18 & 60.0 & 14 & 46.7 & 13 & 43.3 & \\
\hline \multicolumn{8}{|l|}{ Affected site } \\
\hline 1-Extracapsular fracture & 26 & 86.6 & 14 & 46.6 & 13 & 43.3 & \\
\hline Intertrochanteric fracture & 23 & 76.6 & 11 & 36.7 & 10 & 33.3 & \multirow{4}{*}{$.041 *$} \\
\hline Subtrochantric fracture & 3 & 10.0 & 3 & 10.0 & 3 & 10.0 & \\
\hline \multicolumn{7}{|l|}{ 2-Intracapsular fracture } & \\
\hline Femoral neck fracture & 4 & 13.3 & 16 & 53.3 & 17 & 56.6 & \\
\hline \multicolumn{8}{|l|}{ Hospital stay } \\
\hline Mean \pm DS & \multicolumn{2}{|c|}{$9.63 \pm 4.156$} & \multicolumn{2}{|c|}{$13.80 \pm 4.310$} & \multicolumn{2}{|c|}{$15.06 \pm 5.185$} & $0.001 * *$ \\
\hline
\end{tabular}

(*) Statistically significant at $p<0.05 \quad$ (**) highly Significant at 0.05

Table (4): Frequency distribution of studied patients in relation to surgical management and postoperative complications (n=90).

\begin{tabular}{|c|c|c|c|c|c|c|c|}
\hline \multirow{2}{*}{$\begin{array}{c}\text { Variables } \\
\text { Medical management }\end{array}$} & \multicolumn{2}{|c|}{$\begin{array}{c}\text { First group } \\
(\mathrm{n}=30)(18 \text { yrs }<40 \mathrm{yrs})\end{array}$} & \multicolumn{2}{|c|}{$\begin{array}{c}\text { Second group } \\
(n=30)(40<60 \text { yrs })\end{array}$} & \multicolumn{2}{|c|}{$\begin{array}{c}\text { Third group } \\
(\mathrm{n}=30)(\geq 60 \mathrm{yrs})\end{array}$} & \multirow[t]{2}{*}{ P.V } \\
\hline & $\mathrm{N}$ & $\%$ & $\mathrm{~N}$ & $\%$ & $\mathrm{~N}$ & $\%$ & \\
\hline I. Internal fixation & 30 & 100.0 & 19 & 63.3 & 8 & 26.6 & \multirow{6}{*}{$.008 * *$} \\
\hline Dynamic hip screw (DHS) & 28 & 56.7 & 19 & 63.3 & 8 & 26.6 & \\
\hline Intramedullary nail (IMN) & 2 & 6.7 & 0 & 0.0 & 0 & 0.0 & \\
\hline II. Arthroplasty & 0 & 0.0 & 11 & 36.6 & 22 & 73.3 & \\
\hline Bipolar prosthesis & 0 & 0.0 & 11 & 36.6 & 8 & 26.6 & \\
\hline Total hip replacement & 0 & 0.0 & 0 & 0.0 & 14 & 46.6 & \\
\hline \multicolumn{7}{|l|}{ Medical Complications } & \multirow{5}{*}{$.500^{\mathrm{ns}}$} \\
\hline Deep venous thrombosis & 0 & 0 & 1 & 3.3 & 0 & 0 & \\
\hline \multicolumn{7}{|l|}{ Surgical complications } & \\
\hline Bone infection (osteomyelitis) & 0 & 0 & 1 & 3.3 & 0 & 0 & \\
\hline Delayed union & 0 & 0 & 1 & 3.3 & 2 & 6.7 & \\
\hline
\end{tabular}

ns= non-significant

(**) Significant at 0.05

Table (5): Comparison between quality of life for studied patients after 1 year as measured by SF-36 questionnaire (n=90).

\begin{tabular}{|c|c|c|c|c|}
\hline \multirow[t]{2}{*}{ Variables } & $\begin{array}{l}\text { first group less } \\
\text { than } 40 \text { years }\end{array}$ & $\begin{array}{c}\text { second group } \\
40-60\end{array}$ & $\begin{array}{l}\text { third group } \\
\text { more than } 60\end{array}$ & \multirow{2}{*}{$\mathbf{P . V}$} \\
\hline & Mean \pm SD & Mean \pm SD & Mean \pm SD & \\
\hline Physical functioning & $25.633 \pm 7.058$ & $17.533 \pm 5.905$ & $16.500 \pm 7.546$ & $0.001 * *$ \\
\hline Role limitations due to physical health & $0.533 \pm 1.382$ & $0.533 \pm 1.382$ & $2.666 \pm 1.917$ & $0.001 * *$ \\
\hline $\begin{array}{l}\text { Role limitations due to emotional } \\
\text { problems }\end{array}$ & $2.133 \pm 0.345$ & $2.133 \pm 0.345$ & $2.666 \pm 0.479$ & $0.001 * *$ \\
\hline Energy/ fatigue & $16.733 \pm 5.432$ & $10.666 \pm 6.188$ & $14.933 \pm 4.385$ & $0.001 * *$ \\
\hline Emotional well being & $19.433 \pm 2.800$ & $18.133 \pm 2.431$ & $15.366 \pm 3.498$ & $0.001 * *$ \\
\hline Social functioning & $7.933 \pm 2.148$ & $5.866 \pm 2.622$ & $6.700 \pm 2.276$ & $0.001 * *$ \\
\hline Pain & $7.26 \pm 1.362$ & $5.96 \pm 1.586$ & $4.10 \pm 2.106$ & $0.001 * *$ \\
\hline General health & $22.000 \pm 5.913$ & $14.600 \pm 2.061$ & $17.500 \pm 1.479$ & $0.001 * *$ \\
\hline Total quality of life & $95.63 \pm 1.299$ & $93.36 \pm 2.370$ & $83.46 \pm 18.024$ & $0.001 * *$ \\
\hline
\end{tabular}

(**) highly significant at 0.05 
Table (6): Between groups comparisons of quality of life and surgical management (n=90).

\begin{tabular}{|c|c|c|c|}
\hline \multirow{3}{*}{ Surgical management } & \multirow{3}{*}{ N. } & Quality of life & P.V \\
\hline & & \multicolumn{2}{|c|}{ First group 18yrs < 40 yrs $($ Mean \pm SD) } \\
\hline & & Mean \pm SD & \\
\hline Internal fixation & 30 & $95.63 \pm 1.29$ & \multirow[t]{2}{*}{----- } \\
\hline Arthroplasty & -- & --------- & \\
\hline \multicolumn{4}{|c|}{ Second group 40- 60 yrs( Mean \pm SD) } \\
\hline Internal fixation & 19 & $93.73 \pm 2.07$ & \multirow{2}{*}{$.268 \mathrm{~ns}$} \\
\hline Arthroplasty & 11 & $92.72 \pm 2.79$ & \\
\hline \multicolumn{4}{|c|}{ Third group more than 60yrs $($ Mean \pm SD) } \\
\hline Internal fixation & 8 & $55.62 \pm 11.47$ & \multirow[t]{2}{*}{$001 * *$} \\
\hline Arthroplasty & 22 & $93.59 \pm 1.43$ & \\
\hline
\end{tabular}

Table (1): Shows that mean ages of first, second and third group $(28.06 \pm 8.166,53.13 \pm 3.785$ and $64.46 \pm$ 1.136 years respectively). Regarding gender, it was found that the highest percentage in the first group was male while in the second and third group was female $(73.3 \%, 56.7 \%$ and $53.3 \%$ respectively). Also, it was found from this table that; there were statistical significant differences between the three groups regarding their occupation and educational level.

Table (2): Illustrates the health history of studied patients. Diabetes mellitus and hypertension were apparent in the third group greater than in the first and second group $(40.0 \%, 50.0 \%$ and $6.7 \%, 3.3 \%$ and $23.3,13.3 \%$ respectively). Also this table shows that only two patients $(6.7 \%)$ in the second group had pulmonary and tumor disease and four patients in the second group $(13.3 \%)$ had a previous history of corticosteroid therapy. Two patients only in the second group (6.7\%) and five patients in the third group (16.7\%) were smokers.

Table (3): Reflects that; more than half (56.7\%) of studied patients in the first group had exposed to motor car accident while most $(86.7 \%, 96.7 \%)$ of second and third groups falled on ground as a mechanism of injury that led to hip fracture. As regard to the affected site; it was found that extra capsular fracture (intertrochanteric fracture and subtrochantric fracture) was the highest percentage $(86.6 \%)$ in the first group while intracapsular fracture (femoral neck fracture) was the highest percentage $(53.3 \%, 56.6 \%)$ in the second group and third group. There were statistical significant differences between the three groups as regarding to their hospital length of stay.

Table (4): Showed that, the highest percentage of studied patients in the first and second group treated with internal fixation $(100.0 \%, 63.3 \%)$ while majority of patients in the third group treated with arthroplasty (73.3\%). Regarding complication, one patient in the second group (3.3\%) developed deep venous thrombosis, one patient in the second group (3.3\%) had bone infection (osteomyelitis), another patient in the second group $(3.3 \%)$ had delayed union and two patients in the third group $(6.7 \%)$ had delayed union too.

Table (5): Illustrates that, total quality of life mean score of the first age group was better than the second and third group with mean (95.63 \pm 1.299).There was statistical significant difference between the three groups as regard physical functioning, pain and general health.

Table (6): Illustrates that, there was statistical significant improvement in quality of life of the older adult patients who treated with arthroplasty than those who treated with internal fixation. While in the middle adult group; there was statistical significant difference between quality of life for each type of surgical management.

\section{Discussion}

Hip fracture is one of the most important problems that lead to increased dependency, disability and mortality which can affect on patient's quality of life. The incidence of hip fractures increases with age. Age is a significant risk for hip fractures. The incidences vary with different age groups. Our study handled three different age groups exposed to hip fracture to compare quality of life for each group of them (Guirant et al., 2018).

As regard to the demographic characteristics of studied patients, the mean age of the first group was twenty eight years old while the mean age of the second group was fifty three years old and lastly the mean age of third group was sixty four years old. From the researcher's point of view, the first age group represents the young adult and it is the time of work and productivity for those patient, that demand staying out home for long period, performing manual work that increase the risk of exposing to trauma and occupational accidents as our results showed that the 
highest percentage of mechanism of injury among this group was motor car accident.

The present study findings agree with Pillai et al., (2011) who conducted a prospective cohort study "age related incidence and early outcomes of hip fractures" which revealed that ninety patients in group A (patients under the age of sixty four), seven hundred two patients in group B (patients between sixty five and eighty four years) and three hundred eighty five patients in group $C$ (patients over the age of eighty five).

As regard to patients' gender; the present study showed that; the highest percentage in the first group was males while in the second and third group was females. From the researcher's point of view, the highest percentage of male in first group may be due to the concept of our culture; the mens who are responsible for providing and satisfying their families financial demands that increasing their exposure to trauma while the highest percentage of second and third group was females; as we referred previously that mean ages of these two groups were fifty three ,and forty six and this age especially with female is associated with hormonal disturbances or comorbid conditions that may exposing them to fracture. Our study disagreed with Pillai et al., (2011) who revealed that; the majority of patients were females across all the three age groups.

As regard to past health history. The present study noticed that diabetes mellitus and hypertension were apparent in the third group greater than in first and second group. These study findings were in the same line with a study conducted by Mangram et al., (2014) who mentioned that more than half of studied patients had diabetes mellitus and hypertension. Also, Leavy et al., (2017) stated that the vast majority of hip fractures are caused by falls among older people and those with a high prevalence of coexisting disease which predisposing them to falls which lead to hip fracture.

As regard to current health history. The present study revealed that more than half of studied patients in the first group had exposed to motor car accident while most of second and third groups fallen on ground as a mechanism of injury that led to hip fracture. This study findings was supported by Alexiou et al., (2018) who stated that high energy trauma such as motor vehicle accidents are very common among young adult and the falling on ground are the most important cause of hip fractures among the elderly.

Regarding to the affected site; it was found that extra capsular fracture was the highest percentage in the first group while intracapsular fracture was the highest percentage in the second and third group. Our study disagreed with Pillai et al., (2011) who revealed that; a roughly equal distribution of intracapsular and extra capsular fractures among three age groups.

Regarding to hospital length of stay, it was found that the third group stayed more time in hospital than first and second group. From the researcher's point of view, elderly patients have preexisting medical comorbidities that influence on their prognosis and treatment. Also, due to high cost of hip replacement which necessitates them to get state's expenditure approval which require long period of time to be completed.

Regarding to hospital length of stay, it was found that the third group stayed more time in hospital than first and second group. In the researcher's point of view, elderly patients have preexisting medical comorbidities that influence on their prognosis and treatment. Also, due to high cost of hip replacement that necessitate them to do state's expenditure approval which require long period of time to complete it.

The present study showed that; the highest percentage of studied patients in the first and second group treated with internal fixation while majority of patients in the third group treated with arthroplasty. In the researcher's point of view, the femoral head containing very fragile bone in the elderly, sparsely woven cancellous bone that doesn't lend itself to firm internal fixation. Also, the blood supply is disrupted by intracapsular fractures. For this reason intracapsular fractures are treated by hemiarthroplasty and total hip replacement while the young people having high quality of bone and vascularization so they treated with internal fixation. These study finding agree with Pillai et al., (2011) who revealed that; the majority of studied patients in the first group who(less than sixty four year) underwent internal fixation while the majority of studied patients in the second group (between sixty five and eighty four years) and third group (over the age of eighty five year) underwent hemi/total arthroplasty.

As regard to complication; it was found that one patient in the second group had developed deep venous thrombosis, also one patient in the second group had bone infection (osteomyelitis), another patient in the second group had delayed union and two patients in the third group had delayed union too. These study findings disagreed with Carpintero et al., (2014) who revealed that medical complications affect $20 \%$ of patients with hip fracture and complications arising from hip fracture surgery are common, and vary depending on whether the fracture is intracapsular or extracapsular.

As regard to quality of life of the studied patients; the present study revealed that the mean score of quality of life after one year since onset of the trauma of the first age group was better than the second and third 
age group. From the researcher's point of view, the third age group represents elderly patients who have chronic disorders which can affect on their QOL. In the same line (Alexiou et al., 2018) reported that there was a low quality of life among elderly patients with hip fracture who are suffering from preexisting medical comorbidities.

Regarding physical functioning, it was found the first group had improved physical functioning more than the second and third group. In the same line these results agree with (Chang et al., 2019) who reported that elderly people suffering of hip fractures has been a considerable declined in HRQOL is shown during the initial phase after fracture, between the third and fourth months after the fracture, partial recovery is observed in the physical and psychosocial factors. However, these physical and psychosocial aspects do not fully recovered, thereby perpetuating the negative effects of hip fracture on the HRQOL.

On contrast (Gjertsen et al., 2016) found that significant improvements over the period from three to six months after hospital discharge in the functional capacity, the ability to perform activities of daily living, and for most dimensions of the HRQOL of elderly patients with uneventful surgical intervention and adequate rehabilitation following a hip fracture. However, hip fracture patients do not regain their pre-fracture well-being and functional level until one to two years after the fracture. Half of the previously independent patients become partly dependent, and one third became totally dependent after the injury.

These study finding agree with Hajbaghery \& Abbasinia, (2013) who revealed that; the differences between the age groups were statistically significant in all dimensions after twelve months. The youngest age group less than sixty years reported the best quality of life in all dimensions except pain/discomfort after twelve months compared to the older age groups who were more than eighty years reported problems most frequently.

Regarding pain, it was found that the first group had experienced pain more than second and third group. The present study findings agree with Hajbaghery \& Abbasinia, (2013) who revealed that; the youngest age group less than sixty years old, reported sever pain/discomfort after twelve months compared to the older age groups. In the same line (Rogmark et al., 2016) who conducted study title "arthroplasty is better than internal fixation of displaced femoral neck fractures" in which they found better function and less pain after arthroplastycompared to internal fixation in patients over 60 years of age.

Also our study disagreed with (Shyuet al., 2014) who conducted study title "Postoperative pain and its impact on quality of life for hip-fractured older people over 12 months after hospital discharge" which revealed that a quarter of older persons with hip-fractured more than sixty years experienced moderate to very severe pain at six months and one year after discharge.

Another finding from this study; the mean score of quality of life of the older adult patients who treated with arthroplasty was better than those patients treated with internal fixation. This finding agree with Nicolaides et al., (2011) who conducted Arthroplasty versus internal fixation for femoral neck fractures in the elderly which revealed that better outcomes after arthroplasty when compared with internal fixation in terms of overall functional scores, independent ambulation without walking aids, and quality of life. Also, our study agree with( Rogmark and Johnell, 2016) who reported that among people beyond 60 years of age, arthroplasty is associated with better functional outcome, higher health-related quality of life and more independence compared with internal fixation at 12 months.

\section{Conclusion}

This study concluded that quality of life of the first age group was better than the second and third age groups. Also, quality of life of studied patients treated with arthroplasty was better than studied patients treated with internal fixation in third group.

\section{Recommendation}

- Study of factors that affects negatively on patients quality of life.

- Application of rehabilitation program for hip fracture older adult patients to improve their quality of life.

- Replication of the study on a larger probability sample acquired from different geographical areas in Egypt to figure out the main aspects of these conditions and improve health.

\section{References}

1. Abdulmohsin, S., Coons, S., Draugalis, J., and Hays, R., (1997): Translation of the RAND 36item health survey 1.0 (aka SF-36) into Arabic.

2. Alexiou, K., Roushias, A., Varitimidis, S., \& Malizos, K., (2018): Quality of life and psychological consequences in elderly patients after a hip fracture: a review. Clinical interventions in aging, vol (13), p.143.

3. Carpintero, P., Caeiro, J., Carpintero, R., Morales, A., Silva, S., \& Mesa, M., (2014): Complications of hip fractures: A review. World journal of orthopedics, vol (5), No (4), p.402.

4. Chang, W., Kuo, Y., Huang, Y., Tsai, M., \& Chen, Y., (2019):Poor Activities of Daily 
Living Function Reflect Poor Quality of Life after Hip Fracture Surgery for Geriatric Patients. Social Health and Behavior, vol (2), No (2), P.p.13, 143.

5. Jertsen, J., Baste, V., Fevang, J., Furnes, O., \& Engesæeter, L., (2016): Quality of life following hip fractures: results from the Norwegian hip fracture register. $B M C$ musculoskeletal disorders, vol(17),No(1), p.265

6. Guirant, L., Carlos, F., Curiel, D., Kanis, J., Borgström, F., Svedbom, A., \& Clark, P., (2018): Health-related quality of life during the first year after a hip fracture: results of the Mexican arm of the International Cost and Utility Related to Osteoporotic Fractures Study (MexICUROS). Osteoporosis International, vol (29), No (5), p.p1147-1154.

7. Hajbaghery, M., \& Abbasinia, M., (2013): Quality of life of the elderly after hip fracture surgery: a case-control study. Journal of caring sciences, vol (2), No (1), p.53.

8. Leavy, B., Michaëlsson, K., Åberg, A., Melhus, H., \& Byberg, L., (2017): The impact of disease and drugs on hip fracture risk. Calcified tissue international,vol( 100),no(1),p.p 1-12.

9. Lewiecki, E., Wright, N., Curtis, J., Siris, E., Gagel, R., Saag, K., \& Adler, R., (2018): Hip fracture trends in the United States, Osteoporosis International,vol (29), No(3), P.p. 717-722.

10.Mangram, A., Moeser, P., Corneille, M. G., Prokuski, L., Zhou, N., Sohn, J., \& Dzandu, J., (2014): Geriatric trauma hip fractures: is there a difference in outcomes based on fracture patterns?. World Journal of Emergency Surgery, vol (9), No (1), p.59.

11.Nicolaides, V., Galanakos, S., Mavrogenis, A., Sakellariou, V., Papakostas, I., Nikolopoulos, C., \& Papagelopoulos, P., (2011): Arthroplasty versus internal fixation for femoral neck fractures in the elderly. Strategies in Trauma and Limb Reconstruction, vol (6), No(1), p.p 7-12.

12.Pillai, A., Eranki, V., Shenoy, R., \& Hadidi, M., (2011): Age related incidence and early outcomes of hip fractures: a prospective cohort study of 1177 patients. Journal of orthopaedic surgery and research, $\operatorname{vol}(6), N o(1)$, p.5.

13.Prieto-Alhambra, D., Vaquero-Cervino, E., Sierra Setien, I., Sanz \& Sainz, M., (2017): Fracture on health-related quality of life and activities of daily living: Impact of hip SPAREHIP prospective cohort study.p.123.
14.Rogmark, C., \& Johnell, O., (2016): Primary arthroplasty is better than internal fixation of displaced femoral neck fractures: a metaanalysis of 14 randomized studies with 2,289 patients. Acta orthopaedica, vol (77), No(3),p.p 359-367.

15.Shyu, Y., Chen, M., Chen, M., Wu, C., \& Su, J., (2014): Postoperative pain and its impact on quality of life for hip-fractured older people over 12 months after hospital discharge. Journal of Clinical Nursing, vol(18),No(5),P.p 755-764.

16.Sozen, T., Özışık, L., \& Başaran, N., (2017): An overview and management of osteoporosis. European journal of rheumatology, vol (4), No (1), p.46.

17.Sare, J., \& Sherbourne, C., (1992): The MOS 36-Item Short- Form Health Survey(SF36),Conceptual Framework and Item Selection, Medical Care P.p473-483

18. Wiklund R., Toots, A., Conradsson, M., Olofsson, B., Holmberg, H., Rosendahl, E., \& Littbrand, H., (2016): Risk factors for hip fracture in very old people: a population-based study. Osteoporosis International, vol( 27), No(3), P.p.923-931.

19.Zhang, Y., Bo, Q., Lun, S., Guo, Y., \& Liu, J., (2012): The 36-item short form health survey: reliability and validity in Chinese medical students. International journal of medical sciences, vol (9),N(7),p.521. 